\title{
Factors Influencing the Usage of Mobile Phones in East Asia: A Comparative Study Based on the Asian Metropolitan Mobile Survey
}

\author{
Hitoshi Mitomo* and Norio Sanbonmatsu**
}

\begin{abstract}
This paper explores similarities and differences in mobile phone usage between subscribers from five major metropolitan cities across East Asia. Technological advances have been widely adopted by consumers throughout this region, most recognizably via the mobile platform with mobile Internet, email, video-conferencing, e-commerce, and other types of mobile phone-related services becoming critical factors in the daily lives of East Asian consumers. Those living in urban areas have benefited most from these new technologies and services, and more specifically, younger generations have adopted mobile phone-related services far faster than their older counterparts. However little research to date has explored the similarities and differences between mobile phone usage behavior of younger, urban consumers across this region. This paper presents the results of a comparative study of mobile consumer behavior of university students across five major cities including Beijing, Hong Kong, Seoul, Taipei and Tokyo. We found that the dependency of young people on mobile phone services was similar among the cities surveyed, however the specific factors influencing their usage and the communications technologies that they used varied significantly across markets.
\end{abstract}

JEL Classification : O33

Keywords: Asia, Mobile Phone Usage, Communication, Behavior, Comparative Study

\section{Introduction}

East Asia is home to one of the world's largest populations of mobile users. The five Metropolises, Beijing, Hong Kong, Seoul, Taipei and Tokyo, in particular, have a higher mobile subscriber density than any other region in the world. Mobile services in the region have advanced to the stage where, in addition to traditional services such as voice calls and SMS, most users can freely enjoy the latest mobile technologies such as mobile Internet, emailing, e-commerce, e-payment and video-conferencing [5] [7] [11] [12].

Because of this, the utilization of the mobile phone throughout the region has been the subject of great attention by scholars across the world [13]. However, only a few published academic papers have developed comparative studies of behavior across this region. One of the initial studies which compared mobile consumer behavior was conducted by ECOM and

\footnotetext{
* Professor, Graduate School of Global Information and Telecommunication Studies (GITS), Waseda University, Tokyo

** InfoCom Research, Inc.

Received : 31 December 2006 Accepted : 15 October 2007
}

(C) 日本地域学会 (JSRSAI) 2007 
Infocom Research as a part of the Worldwide Mobile Internet Surveys. Their first study was conducted in Korea, Hong Kong and Japan in December 2001 [4] [5]. Minges [10] compared the usage of the mobile Internet within Asia-Pacific economies by using aggregate usage data. However, even within these studies, the information provided on mobile communications commonly presents only macro-level statistics, making it difficult to understand the various aspects of "real mobile life" based on behavioral insights [8] [9]. And while a single research format is typically applied in the Western world, the existence of different systems, services, and cultures of mobile phone usage within the East Asia region creates a far more complex environment in which mobile phone usage behavior must be explored.

Therefore, we have initiated this research to help better understand the commonalities and differences influencing mobile phone usage in the region. Five symbolic metropolitan cities namely Beijing, Hong Kong S.A.R., Seoul, Taipei, and Tokyo were selected and we sampled over a thousand university students in each city, to ask their choice and use of mobile phones.

We first apply statistical and multivariate analysis methods to explore differences and similarities of mobile phone usage. Next, we explore the impact that such factors have upon overall communications behavior of young mobile users. Finally, we focus upon the choice of the second generation $(2 \mathrm{G})$ versus the third generation $(3 \mathrm{G})^{1}$ of mobile phone technologies and the impact that these have upon communications behavior across regions. The results suggest that despite a variety of cultural, environmental, political and economic factors, young people in these cities share behavioral patterns in choice and usage of mobile phone services.

This paper is organized as follows: Section 2 shows the outline of the questionnaire. Primary data collected from the survey is briefly analyzed in Section 3. Section 4 focuses on differences and similarities in the usage of mobile phones. Section 5 identifies the factors influencing the usage or choice of technologies for mobile phones. Section 6 concludes the paper.

\section{The Survey}

\subsection{Outline of the questionnaire}

The questionnaire contains 33 questions that are classified into five categories concerning behavior; 10 additional questions related to demographic attributes are also included. The five categories include: usage of mobile, brand loyalty and upgrading, communication through mobile, new services and handsets, and media literacy. These questions are designed to test the hypotheses formulated prior to fielding the survey.

The survey sample was confined to university students in each of the five major cities because such students typically possess similar attributes and are the most intensive and extensive users of mobile phones [1] [14].

The survey was conducted between November 2004 and January 2005 at major univer-

${ }^{1}$ The second generation $(2 \mathrm{G})$ is currently the most prevailed digital mobile technology, including GSM, cdmaOne, PDC, etc. The third generation (3G) provides higher data speeds and additional services such as Internet access, video-telephone and music downloading, with $2.5 \mathrm{G}$ enabling high speed data transfer over $2 \mathrm{G}$ networks, as a bridge between $2 \mathrm{G}$ and $3 \mathrm{G}$. 
Table 1. The Questionnaire

\begin{tabular}{|l|l|l|}
\hline Categories & & Questions \\
\hline \multirow{4}{*}{ Usage of mobile } & Q. 1-5 & Tariff, handset, service, etc. \\
\cline { 2 - 3 } & Q. $6-7$ & Phone bill payment \\
\cline { 2 - 3 } & Q. $12-17$ & Frequency and content of calls and SMS/emails \\
\cline { 2 - 3 } & Q. 18 & The number of records in the phone book \\
\hline \multirow{3}{*}{ Brand loyalty and upgrading } & Q. $8-11$ & Choice of mobile operator and handset in use \\
\cline { 2 - 3 } & Q. $22-23$ & Satisfaction with current service and handset \\
\hline \multirow{2}{*}{ New services and handsets } & Q. $19-20$ & Communication with friends and acquaintances \\
\hline & Q. 21 & Willingness to use new advanced services and functions \\
\hline Media literacy & Q. 24-25 & Mobile number portability and the willingness to pay \\
\hline & Q. 26-33 & Usage of other media \\
\hline
\end{tabular}

sities of each city, with the cooperation of a range of professors and their students ${ }^{2}$. Due to difficulties in random sampling, the questionnaires were distributed and collected during scheduled classes. Hence, results may contain certain biases that should be taken into account. Table 1 above summarizes the questionnaire ${ }^{3}$.

\subsection{Demographic Information}

Table 2 shows basic demographic results of the sample. Over one thousand responses were collected from each city. The overall sample includes 6,072 respondents, including 55 (0.91\%) whose gender is unknown.

Table 3 shows the averages of age, monthly expenditure on mobile phone usage and

Table 2. The Number of Respondents

\begin{tabular}{|l|r|r|r|r|}
\hline Location & $\begin{array}{c}\text { Total number of } \\
\text { respondents }\end{array}$ & & \\
\hline Beijing & 1,003 & 482 & 521 & 0 \\
\hline Hong Kong & 1,003 & 432 & 555 & 16 \\
\hline Seoul & 1,525 & 1,004 & 515 & 6 \\
\hline Taipei & 1,503 & 989 & 491 & 23 \\
\hline Tokyo & 1,038 & 657 & 371 & 10 \\
\hline Total & 6,072 & 3,564 & 2,453 & 55 \\
\hline
\end{tabular}

\footnotetext{
${ }^{2}$ Samples were distributed over 4 universities in Beijing, 9 universities in Hong Kong, 9 universities in Seoul, and 6 universities in Tokyo. In Taipei, the survey was carried out in cooperation with Rotary Foundation in Taiwan, so that samples were collected from various universities.

${ }^{3}$ Besides the fill-in survey, an online survey was carried out in Japan.
} 
Table 3. Average Age, Expenditure on Mobile and Monthly Disposable Income

\begin{tabular}{|l|c|l|l|r|}
\hline Location & Average & & & \\
\hline & Age & Expenditure on Mobile Phone (A) & Monthly Disposable Income (B) & $(\mathrm{A}) /(\mathrm{B})$ \\
\hline Beijing & 20.07 & US\$10.75 (CNY88.99) & US\$128.41 (CNY1,062.77) & $8.37 \%$ \\
Hong Kong & 22.59 & US\$19.88 (HKD154.50) & US\$367.88 (HKD2,859.26) & $5.40 \%$ \\
Seoul & 23.65 & US\$54.68 (KRW56,599.87) & US\$318.73 (KRW329,920.20) & $17.16 \%$ \\
Taipei & 22.21 & US\$24.88 (NTD789.55) & US $\$ 272.74($ NTD8,656.87) & $9.12 \%$ \\
Tokyo & 20.91 & US\$85.63 (JPY8,792.13) & US $\$ 430.03(J P Y 44,155.82)$ & $19.91 \%$ \\
\hline
\end{tabular}

Exchange Rate as of Dec. 31, 2004

monthly disposable income. Since all respondents are university students, the age should average around twenty years old. Slightly higher averages were found in Seoul and Hong Kong, mainly due to military obligation (Seoul) and working students (Hong Kong).

Although the direct comparison of average monthly spending for mobile phone use between cities is almost meaningless, the ratios of these amounts with the corresponding monthly disposable income levels $((\mathrm{A}) /(\mathrm{B}))$ suggest that students in Seoul and Tokyo pay double or even triple for their mobile phone services relative to respondents from other cities. Students in Seoul and Tokyo may enjoy the most advanced mobile technologies and services, but actually bear a heavier burden than consumers in other regions.

\section{Primary Data Analysis}

\subsection{Summary of the findings}

Findings from the primary data analysis can be summarized as follows:

1. Most respondents have used mobile phones for more than five years except in Beijing. In Beijing, most of them have used mobile phones for only one or two years.

2. For more than half of the respondents, mobile phone bills are paid by family members. This suggests that economic parameters such as the tariff rate cannot work effectively to discriminate between different usage behavior as traditional economic theory assumes, because these consumers do not bear financial responsibility for their mobile phone use.

3. In Beijing, Hong Kong and Taipei, respondents tend to choose a mobile service provider and handset by word of mouth from family members and friends. In Seoul and Tokyo, the majority of consumers rely more heavily on official information provided by service providers or from the Internet.

4. At an international level, phone calls and SMS/emails are substitutes. Respondents in Hong Kong, Seoul and Taipei make more mobile phone calls than those in Beijing and Tokyo. Conversely, those in Beijing, Seoul and Tokyo send more SMS/emails than those in Hong Kong and Taipei.

5. Both phone calls and SMS/emails have weak or almost no correlation with the number of recipients that send or receive such communications.

6. Phone calls and SMS/emails are somewhat complementary to each other at an individual (micro) level although substitutable at an international (macro) level as suggested above.

7. Among the metropolises, no similarity can be found in the reasons for choosing a mobile 
service provider and in the factors that influence the choice of mobile phone operators and handsets excluding suggestions from a salesperson.

The rest of this section explains our findings in more detail.

\subsection{Basic statistics}

While our overall survey covered a wide range of topics, in this paper we concentrate upon the similarities and differences across the duration of mobile phone use ; the responsible party for mobile service payment; the factors that influence the choice of mobile phone operators (service providers) and handsets ; and the number of incoming and outgoing phone calls and SMS/emails made.

\subsubsection{Duration of mobile phone use}

Figure 1 shows the duration of mobile phone use. Except in Beijing, most respondents answered " 5 years or more", which means that these respondents began using a mobile phone when they were approximately 15 years old. In Beijing however, most respondents answered "1-2 years" which means that they began using a mobile phone much later in their lives, obtaining a mobile phone only after entering university.

\subsubsection{Who actually pays the mobile phone bill}

Answers to the question of who pays for the mobile phone bill demonstrate strong dependency upon family members for all survey respondents. Approximately half of all respondents answered that their mobile phone bills were "paid by family" (see Figure 2). One reason for such results is that "family discount" plans offered by mobile operators provide families possessing two or more lines with a special discount. Another reason for such responses is the simple fact that university students do not typically hold full-time or well-paying jobs, and therefore rely upon their parents for their tuition fees and living expenses until they graduate. Parents therefore pay their children's phone bill as part of this financial support.

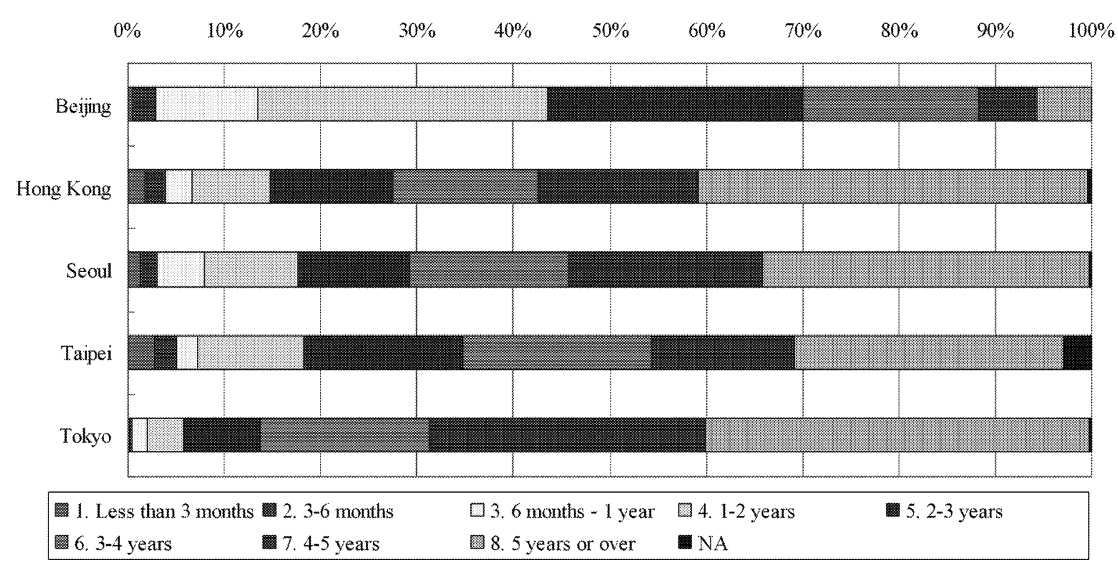

Figure 1. Duration of Mobile Phone Use 


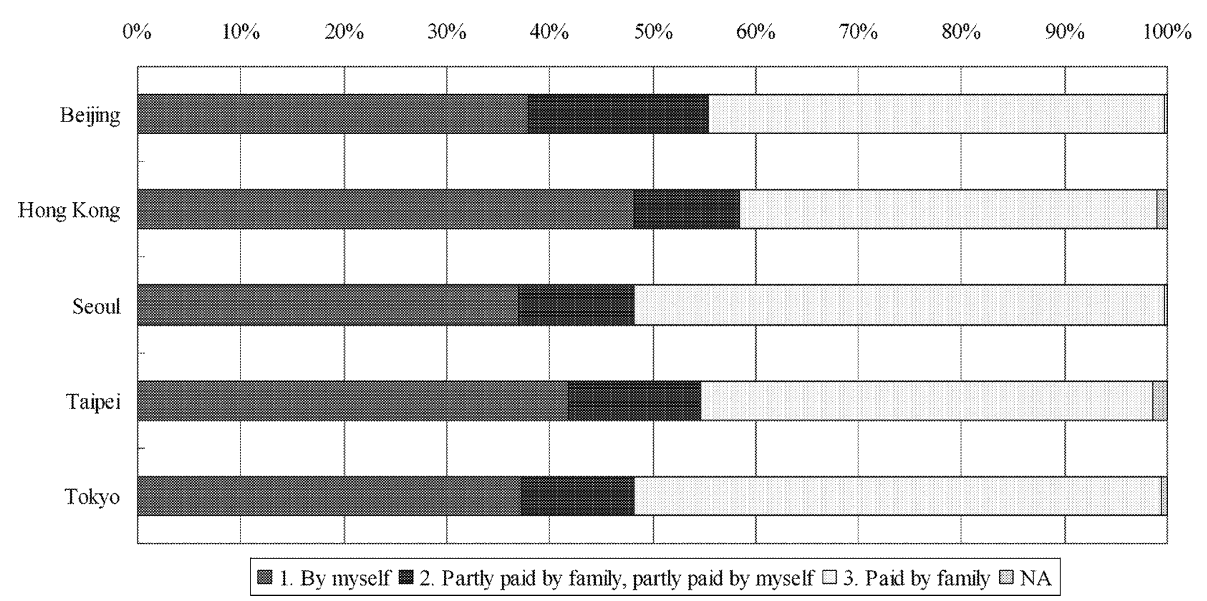

Figure 2. Actors paying the mobile phone bill

\subsubsection{Factors that influence the choice of mobile phone operators and handsets}

Figure 3 presents the factors that have a decisive influence on the choice of mobile service providers. In Seoul, the most influential power comes from "Information obtained from the Internet", while in Tokyo it is "Information obtained from the mobile phone service provider's service counter". Since mobile operators supply both telecommunications services and mobile handsets as a package in these two cities, there is a heavier burden upon these operators to provide detailed and integrated information about their mobile service packages than carriers in other regions. Because of this, consumers appear to rely more heavily on this official information than on word of mouth channels. In other areas, families and close friends show a stronger influence. Certainly, the level of influence of families and friends is not so low even in Seoul and Tokyo, but it is not the most crucial factor.

Figure 4 shows various determinant factors in choosing a mobile handset. In Seoul, the most influential factor again appeared to be "Information obtained from the Internet", and in Tokyo, "Information obtained from the mobile phone service provider's service counter".

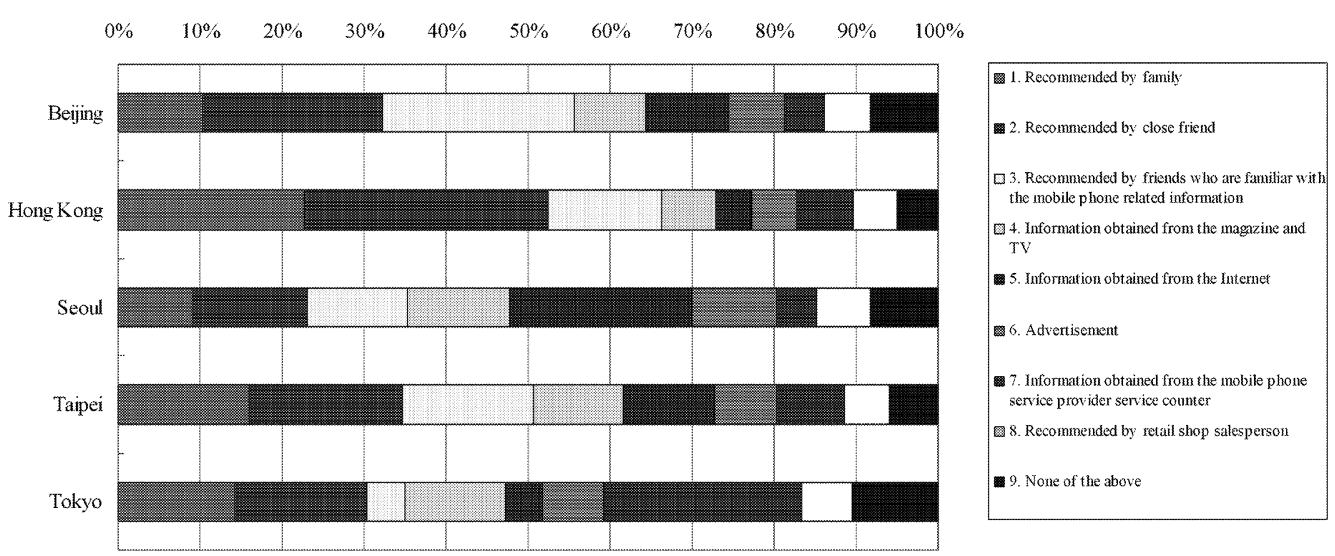

Figure 3. Factors that influence the choice of mobile phone operators 


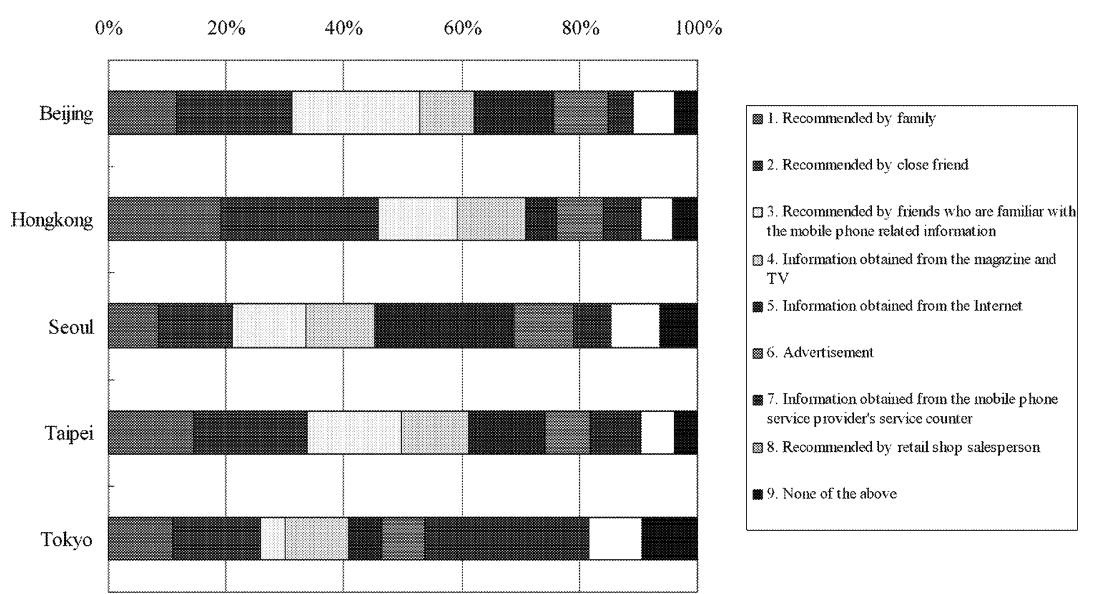

Figure 4. Factors that influence the choice of mobile handsets

In these two cities, handsets are not sold separately under the brand of the manufacturers but under that of the mobile operator. People in these cities therefore tend to collect information directly from operators, instead of from other sources because they provide official, integrated and detailed information.

\subsubsection{Number of phone calls and SMS/emails}

Figure 5 presents the frequency of incoming and outgoing calls. In Hong Kong, Seoul and Taipei, more than $70 \%$ of the respondents use voice calls at least $3-4$ times per day, but in Beijing and Tokyo, less than $30 \%$ do so.

On the other hand, SMS or mobile emails are more widely used in Beijing, Seoul and Tokyo than in Hong Kong and Taipei (see Figure 6) ; more than 70\% of the respondents use mails at least 3-4 times a day. The reasons why respondents in Beijing utilize SMS are : i) SMS is less expensive and a uniform rate is applied; ii) phone calls are charged based on the Both-Party-Pay (BPP) principle, where people pay for incoming calls as well. In Japan, SMS is less popular and people generally use mobile emails. Phone calls are relatively

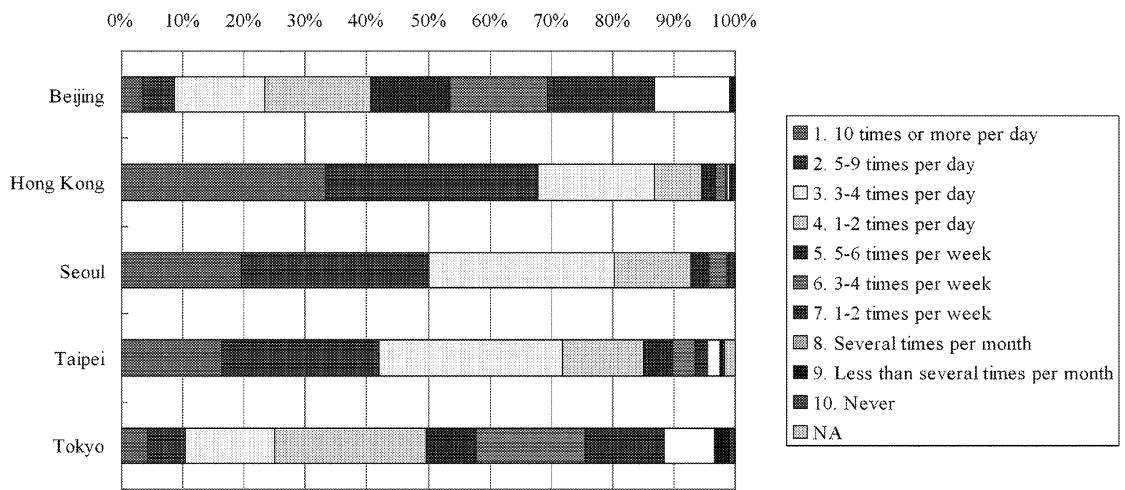

Figure 5. The number of incoming and outgoing phone calls 


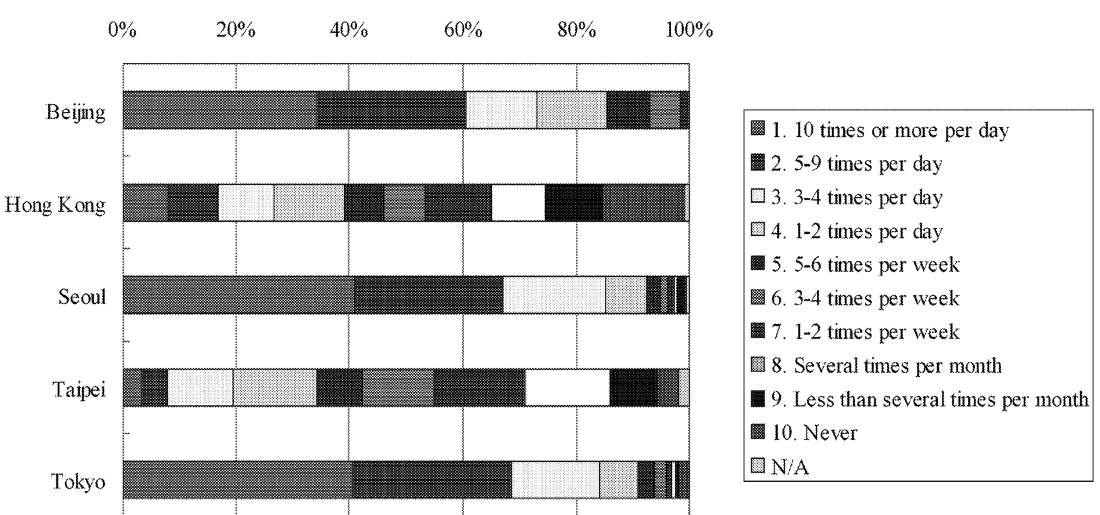

Figure 6. The number of incoming and outgoing SMS or emails

expensive and people tend to avoid disturbing others by such means. As a result, they prefer sending emails to making phone calls. It seems that, except in Seoul, SMS/emails and phone calls are substitutes in communications at a macro level. In the area where people do utilize phone calls, SMS/emails are less utilized, and vice versa. However, in Seoul, they utilize both.

\section{Differences and Similarities in the Usage of Mobile Phones}

Statistical approaches could bring about new findings that cannot be seen in a primary analysis. In this paper, several statistical methods are applied for the following objectives :

i) To identify the relationship between

a) the number of recipients and the number of phone calls;

b) the number of recipients and the number of SMS/emails ;

c) the frequencies of phone calls and SMS/emails.

ii) To examine

a) if the reasons for choosing a mobile service provider are identical among the five metropolises ;

b) if the factors that influence the choice of mobile phone operators and handsets are identical among the five metropolises.

\subsection{Intensiveness of communication-correlation analysis}

To identify the relationship of $\mathrm{i}-\mathrm{a}$ ) through $\mathrm{i}-\mathrm{c}$ ) listed above we apply correlation analysis. The correlation coefficients are given in Table 4 .

The analyses $i-a)$ and $i-b)$ aim to examine whether communication among young people is intensive or extensive. If the number of recipients and the number of calls or SMS/emails have a strong positive correlation, it is likely that those who place more calls or SMS/emails have more communication partners. Their communication is extensive in the sense that more contacts result from having more partners. If not, their communication is intensive because they tend to communicate with only specific partners, and increases in communication stem from contacting those with whom they already have close connections more frequently. It is apparent from the values in the first two rows in Table 4 that both phone 
Table 4. Correlation coefficients

\begin{tabular}{|c|c|c|c|c|c|}
\hline & Beijing & Hong Kong & Seoul & Taipei & Tokyo \\
\hline i-a) & 0.517 & 0.212 & 0.187 & 0.148 & 0.314 \\
\hline i-b) & $-0.012^{*}$ & 0.289 & 0.185 & 0.331 & 0.238 \\
\hline i-c) & 0.244 & 0.424 & 0.29 & 0.313 & 0.248 \\
\hline
\end{tabular}

* Not significant.

All values other than this case are significant at $1 \%$ level.

calls and SMS/emails have weak or almost no correlation with the number of recipients in all the metropolises.

The analysis $\mathrm{i}-\mathrm{c}$ ) looks into the correlation between the frequencies of phone calls and SMS/emails. If the correlation coefficient is positive (negative), those who are making more phone calls are believed to be sending more (less) SMS/emails. The third row in Table 4 indicates that the correlations are slightly positive in all locations. This suggests that phone calls and SMS/emails are somewhat complementary to each other at an individual (micro) level.

\subsection{Homogeneity among the Metropolises-Chi-square test}

To deal with the problems ii)-a) and ii)-b), we apply a chi-square test. The test analyzes the difference in the average values of two or more sample groups. As an initial analysis, we examine whether any common tendency among the metropolises can be found in the answers ${ }^{4}$. Here we concentrate on asking the following questions; a) the reasons for choosing the mobile service provider, and b) the factors that influence the choice of the mobile phone operator and handset.

The first question provides twenty alternatives (see Table 5) and the respondents were allowed to make multiple choices. For each alternative, the respondents can be categorized into two groups : marked and non-marked. The null hypothesis states that the respondents' choice (the ratio of the marked) is the same among all the metropolises. For both cases, with and without assuming the normal distribution of the population, the null hypothesis was rejected at the $5 \%$ significance level for every choice alternative ${ }^{5}$. This suggests each choice alternative has a different level of importance for respondents within each region and a single dominant reason for their choice of mobile service provider could not be found.

As for the second question, only the null hypothesis for the alternative "recommended by retail shop's salesperson" could not be rejected both for mobile service providers and handsets (See Table 6 for the choice alternatives). Therefore, suggestions from a salesperson appear to hold similar levels of importance in choosing a mobile service provider and handset in these five cities.

\footnotetext{
${ }^{4}$ Examining similarities or differences in some specific pairs of the metropolises is left to future research.

${ }^{5}$ The Pearson statistics and the likelihood ratios were calculated for the cases of normal distribution of the population and a non-parametric assumption, respectively.
} 
Table 5. Alternatives for the reasons for the choice of a mobile service provider

\begin{tabular}{|c|c|}
\hline \multicolumn{2}{|r|}{ Choice Alternatives } \\
\hline 1) & Cheap monthly service plan \\
\hline 2) & Contains various discount services \\
\hline 3) & Monthly charge can be carried forward \\
\hline 4) & Extensive service network coverage \\
\hline 5) & Service network coverage within train and subway \\
\hline 6) & High quality of voice standard \\
\hline 7) & Charge for sending or receiving emails/SMS \\
\hline 8) & No delayed emails/SMS \\
\hline 9) & Numbers of characters allowed for sending or receiving emails/SMS \\
\hline 10) & Junk/spam emails filtering function \\
\hline 11) & Speedy connection \\
\hline 12) & Contains various mobile phone contents services \\
\hline 13) & Possess a high mobile phone device quality and design \\
\hline 14) & High standard of functionality \\
\hline 15) & Image of the mobile phone company \\
\hline 16) & Image from advertising \\
\hline 17) & Recommended by friends \\
\hline 18) & Most of my friends are currently using \\
\hline 19) & Joining together with family/company \\
\hline 20) & Others \\
\hline
\end{tabular}

Table 6. Alternatives for factors influencing the choice of mobile service providers and handsets

\begin{tabular}{|l|}
\multicolumn{1}{|c|}{ Choice Alternatives } \\
\hline 1)
\end{tabular}

\section{Factors Influencing the Usage of Mobile Phones}

There are various factors that influence the usage of mobile phones and the communications made through them, including: economic, social, historical, personal, technological, locational, cultural, ethnic, etc. Among these and many others, we focus upon two factors: "locational" and "technological". By "locational", we mean that communication behavior could be different based upon geographic location, thus reflecting various hidden factors in the location itself. And by "technological", we mean that specific elements inherent in the technology will lead to different usage behavior. In this section, we deal with two specific 
problems :

iii) To visualize how the content of communication varies by location.

iv) To determine the factors influencing the usage choice of individual technologies.

\subsection{Location and the content of communication-corresponding analysis}

The purpose of this section is to identify similarities or differences between respondents from different cities with respect to their locational and technological usage of the mobile platform. To do so, we apply cross tabulation analysis. In our survey, we asked questions related to the actual content of the phone call and SMS/emails made via the mobile phone. These contents were categorized into four levels based on the importance of the communicated messages, which include: (1) Important decision-making issues, (2) Steps and procedures clarification, (3) Small talk, and (4) Gossip. The result is shown in Figs. 7 and 8.

The following tendencies could be found:

a) The respondents in Seoul and Tokyo communicate through both mobile phone calls and SMS/emails on more important matters than those in the other cities.

b) Those in Beijing, Hong Kong and Taipei regard phone calls as a more important communication means than SMS while those in Seoul and Tokyo place almost the same importance on phone calls and SMS/emails.

c) In Taipei, $3 \mathrm{G}$ users seem to display a slightly different behavior in mobile phone communications compared with $2 \mathrm{G}$ users. However, in other cities, such differences are not evident.

d) With regard to SMS/email communications, 2G and 3G users in Taipei and Hong Kong show a different usage behavior, while no such differences exist in other markets.

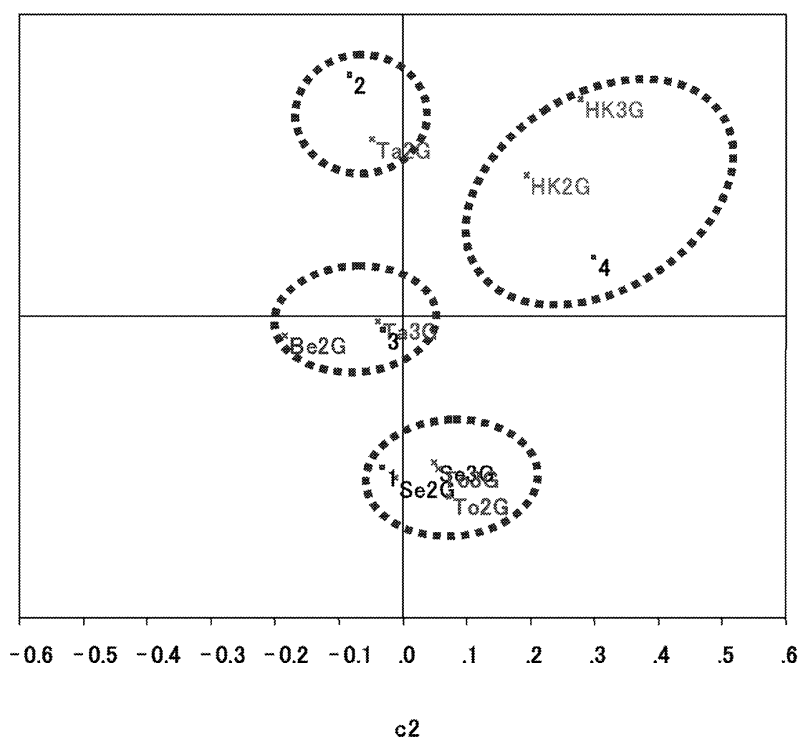
Be: Beijing
HK: Hong Kong
Se: Seoul
Ta: Taipei
To: Tokyo

Figure 7. Location and content of phone communication 


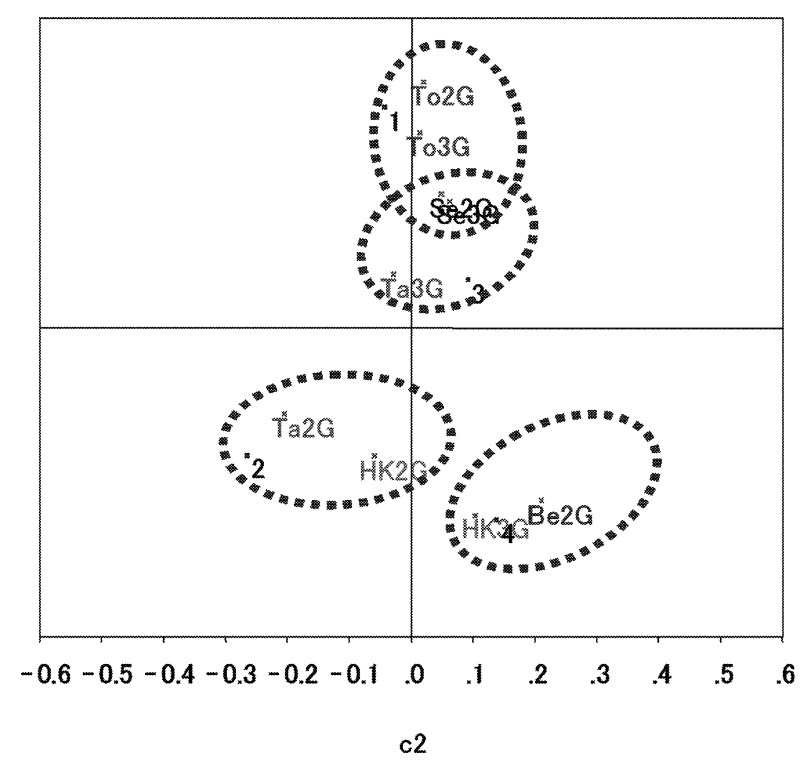

Be: Beijing

HK: Hong Kong

Se: Seoul

Ta: Taipei

To: Tokyo

Figure 8. Location and Content of SMS/email Communication

\subsection{Factors influencing the choice of technologies - Logit analysis}

In order to explore the factors that influence technology usage or choice, and to estimate their level of influence, a logit analysis is applied. The explained variable is the choice of $2 \mathrm{G}$ or $3 \mathrm{G}$ technologies. The explanatory variables we consider are : (1) Phone bill (below/ above the average), (2) Frequency of phone calls, (3) Frequency of SMS/e-mails, (4) Gender (male/female), (5) Fulltime/working students, and (5) Disposable income (below/above the average).

The details for these variables are given in Table 7. The model can be formulated as follows :

$$
\operatorname{logit}[P(Y=3 G)] \equiv \log \left[\frac{P(Y=3 G)}{1-P(Y=3 G)}\right]=\beta_{0}+\beta_{1} x_{1}+\beta_{2} x_{2} \cdots \cdots
$$

where $P(Y=3 G)$ : Probability of the choice of $3 G$

$x_{i}$ : Explanatory variables

$\beta_{i}$ : Estimated parameters

If $\beta_{1}$ is positive, the corresponding explanatory variable increases the choice of $3 \mathrm{G}$. If negative, it increases the choice of $2 \mathrm{G}$.

The cities are classified into low and high $3 \mathrm{G}$ penetration groups. The former includes Beijing, Hong Kong and Taipei, and the latter Seoul and Tokyo. The models for both the low and high penetration groups are significant (the $\mathrm{p}$-values are 0.002 and 0.001 , respectively), and the results can be summarized as follows:

[The low penetration group]

a) The use of $3 \mathrm{G}$ in these cities is characterized both by female users and a high frequency of SMS/e-mails. Conversely, male users tend to remain $2 \mathrm{G}$ users. 
b) Those with lower phone call frequency are in favor of $3 \mathrm{G}$.

c) Economic factors such as phone bill and disposable income are not significant. [The high penetration group]

a) The use of $3 \mathrm{G}$ is characterized by both a high frequency of phone calls and by fulltime students.

b) Economic factors, gender and frequency of SMS/e-mails are not significant.

An exact tendency could not be found in the factors influencing the choice and usage of advanced $3 \mathrm{G}$ technology.

\section{Implications and Conclusion}

Although the five cities in the study are situated within East Asia, the patterns of communication behavior are not consistent between consumers in these markets. The differences stem from a wide range of factors including cultures, history, political systems, languages and many other factors. What is consistent, however, is that mobile technologies have enabled the younger generations within these cities to communicate with one another on a more personal, frequent and expansive basis than ever before. The results of our correlation analysis show that phone calls and SMS/emails have a weak positive correlation, which means that they are complements at a personal level. This suggests that mobile phones have enhanced the ability to create "weak ties" among friends, a concept which Granovetter [6] identified from an analysis of interpersonal networks. Such weak ties are characterized by weak interpersonal relationships but offer a platform for efficient information sharing and retrieval because of low redundancy of communications between individuals [3].

However, our primary data analysis indicates that phone calls and text messages are substitutes for one another at the international level. While these two results may at first seem contradictory, they actually are not because the former describes the tendency that people who make more calls send more SMS/emails but does not define any consequence from aggregation at the international level.

The chi-square test indicates that motivations to choose an operator and a handset are not identical between respondents from different countries in this region. In other words, a set of technologies which have been accepted in one place will not necessarily be accepted in another. Information sources which people use to make their consumption and usage decisions also vary by country. Our results suggest that policy makers, mobile operators and handset manufacturers should create targeted promotion policies and strategies specific to each market. The introduction of a policy or marketing strategy which is successful in one city will not lead to similar success in another.

Mobile technologies are shifting from $2 \mathrm{G}$ to $3 \mathrm{G}$, but adoption levels differ significantly by country. In Tokyo and Seoul, $3 G$ mobile penetration rates have gained dominance over $2 \mathrm{G}$, while in other areas we studied, such shifts have yet to occur. And our correspondence analysis shows that the adoption of this new 3G technology has not affected the ways in which university students communicate with either voice or text-based conversations. Although certain geographical tendencies exist in the usage of the mobile platform, technological advances appear to be completely invisible to end users. Some advocates suggest that technological advancements spur advances in usage, but our research finds no evidence 
to support this claim. From an Economics perspective, mobile phone communications can be regarded as derived demand. If consumers can develop new ways of communicating with new technologies, drastic changes in usage will be realized. However, the logit analysis has found that users in each city have their own specific reasons for adopting new technologies, failing to identify any common factors across respondents from these five cities. These findings suggest then that a complex array of individualized factors influence mobile technology adoption and usage behavior within the East Asia region, as no clear or shared factors emerged from our analyses.

East Asia is leading the world in terms of advances uses of the mobile phone. Our research effort has explored specific ways in which consumers within this region use their mobile phones within their daily lives. Five representative metropolitan areas were selected within which to study behavior of university students who are the most intensive and extensive users of the mobile platform. Many similarities and differences were found between consumers in these markets, leading us to conclude that no universal policies or strategies will succeed in this region.

Our analysis is however still not finished and further investigations are necessary. A variety of additionally analyses will provide even deeper insights and could add further contributions to this area of research, using more advanced behavioral modeling [2]. Examples of such analyses could include the analysis of users' choice behavior between mobile mailing (SMS/emails) and PC emailing in terms of economic and demographic factors as well as network externalities; and to identify the ways in which the value, function and role of mobile phones and experienced by your consumer in comparison to other media channels such as TV, radio, newspapers, magazines and the Internet.

\section{Acknowledgements}

This research is in part supported by Grants-in-Aid Scientific Research (B)17330070. The authors would like to thank Toshiya Jitsuzumi, Yuji Mori, Tokio Otsuka, Hiroyuki Someya, Aeri Kim, Yoko Harada and other members of the project for their kind support. They are indebted to Philip Sugai for his valuable comments on the paper. They would like also thank many organizations, universities, scholars, students and friends for their cooperation with our survey.

\section{References}

[1 ] Aoki, K. and Downes, E.J., "An analysis of young people's use of and attitudes toward cell phones," Telematics and Informatics, Vol. 20, 2003, pp. 349-364.

[2] Adeson, J.G. and Gerbrung, D.W., "Structural Equation Modeling in Practice: A Review and Recommended Two-Step Approach,” Psychological Bulletin, Vol. 103, No. 3, 1988, pp. 411-423.

[ 3 ] Cooper, G., The mutable mobile : Social theory in the wireless world, in Brown, B., Green, N., and Harper, R. (eds.), Wireless world: Social aspects and interactional aspects of the mobile age, London (UK), Springer, 2001, pp. 19-31.

[ 4 ] ECOM, Actual Situation and Future Trend of the Use of Mobile Internet. http://www.ecom.jp/ ecom_e/latest/ecomjournal2004/WG9_a.htm, 2004.

[5] ECOM and InfoCom Research, Inc., $2^{\text {nd }}$ Worldwide Mobile Internet Survey Project http : //www.icr.co.jp/info/press/press20021210.pdf (in Japanese), 2002. 
[6 ] Granovetter, M., "The Strength of Weak Ties," American Journal of Sociology, Vol. 78, No. 6, 1973, pp. 1360-1380.

[ 7 ] Ishii, K., "Internet use via mobile phone in Japan," Telecommunications Policy, Vol. 28, 2004, pp. 4358.

[ 8 ] Kerlinger F.N. and Lee H.B., Foundations of Behavioral Research. Wadsworth Pub Co, 1999.

[9 ] Lobet-Maris C., Mobile phone tribes: Youth and social identity, in Fortunati, L., Katz, J.E. and Riccini, R. (eds.) Mediating the Human Body: Technology, Communication and Fashion, Mahwah, NJ, Lawrence Erlbaum, 2003, pp. 87-92.

[10] Minges, M., "Is the Internet mobile? Measurements from the Asia-Pacific region," Telecommunications Policy, Vol. 29, 2005, pp. 113-125.

[11] Nomura Research Institute, Ltd., Cyber Life Observations Study on the Japanese Consumers' Use of Information \& Telecommunications Equipment and Services, http://www.nri.co.jp/english/ news/2002/021120/021120.pdf, 2002.

[12] Rice R.E. and Katz J.E., "Comparing Internet and mobile phone usage : digital divides of usage, adoption, and dropouts," Telecommunications Policy, Vol. 27, 2003, pp. 597-623.

[13] Weber A., and Wingert B., "i-mode" in Japan: How to Explain its Development, 15th Biennial Conference of the International Telecommunication Society, Berlin/Germany, 2004

[14] Wilska, T.-A., "Mobile Phone Use as Part of Young People's Consumption Style," Journal of Consumer Policy, Vol. 26, 2003, pp. 441-463. 